\title{
ANALYSIS OF LIQUEFACTION CHARACTERISTICS AT CHRISTCHURCH STRONG MOTION STATIONS
}

\author{
Liam WOTHERSPOON ${ }^{1}$, Rolando ORENSE ${ }^{2}$, Russell GREEN $^{3}$, Brendon BRADLEY $^{4}$, Brady $^{2}$

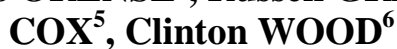

\begin{abstract}
The city of Christchurch and its surrounds experienced widespread damage due to soil liquefaction induced by seismic shaking during the Canterbury earthquake sequence that began in September 2010 with the $\mathrm{M}_{\mathrm{w}}$ 7.1 Darfield earthquake. Prior to the start of this sequence, the city had a large network of strong motion stations (SMSs) installed, which were able to record a vast database of strong ground motions. This paper uses this database of strong ground motion recordings, observations of liquefaction manifestation at the ground surface, and data from a recently completed extensive geotechnical site investigation program at each SMS to assess a range of liquefaction evaluation procedures at the four SMSs in the Christchurch Central Business District (CBD). In general, the characteristics of the accelerograms recorded at each SMS correlated well with the liquefaction evaluation procedures, with low liquefaction factors of safety predicted at sites with clear liquefaction identifiers in the ground motions. However, at sites that likely liquefied at depth (as indicated by evaluation procedures and/or inferred from the characteristics of the recorded surface accelerograms), the presence of a non-liquefiable crust layer at many of the SMS locations prevented the manifestation of any surface effects. Because of this, there was not a good correlation between surface manifestation and two surface manifestation indices, the Liquefaction Potential Index (LPI) and the Liquefaction Severity Number (LSN).
\end{abstract}

Keywords: Liquefaction, Canterbury earthquake sequence, CPT, SPT, shear wave velocity

\section{INTRODUCTION}

The city of Christchurch is located on the east coast of the South Island of New Zealand, on the edge of the Canterbury Plains, a large area (approximately $160 \mathrm{~km}$ long and up to $60 \mathrm{~km}$ wide) formed by the overlapping alluvial fans of glacier-fed rivers. The surface geology within the city consists primarily of the Springston Formation Holocene alluvial gravels, sands and silts that are highly susceptible to liquefaction, and the Christchurch Formation dense dune and beach sands that are less susceptible to liquefaction (Brown \& Weeber 1992).

\footnotetext{
${ }^{1}$ EQC Research Fellow, Department of Civil \& Environmental Engineering, University of Auckland, Auckland, New Zealand, Email: 1.wotherspoon@auckland.ac.nz

${ }^{2}$ Associate Professor, Dept. of Civil \& Environmental Engineering, University of Auckland, New Zealand

${ }^{3}$ Professor, Dept. of Civil \& Environmental Engineering, Virginia Tech, USA

${ }^{4}$ Senior Lecturer, Dept. of Civil \& Natural Resources Engineering, University of Canterbury, New Zealand

${ }^{5}$ Associate Professor, Dept. of Civil, Architectural \& Environmental Engineering, The University of Texas, USA.

${ }^{6}$ Assistant Professor, Department of Civil Engineering, University of Arkansas, USA
} 
The city and some surrounding towns experienced widespread damage due to soil liquefaction induced by seismic shaking during the Canterbury earthquake sequence, beginning in September 2010 with the $\mathrm{M}_{\mathrm{w}}$ 7.1 Darfield earthquake. The other most notable earthquakes in this sequence were the February 22 $2011 \mathrm{M}_{\mathrm{w}} 6.2$ Christchurch earthquake, and the two twin earthquake events on 13 June 2011 and 23 December 2011. Each resulted in widespread liquefaction induced damage.

Prior to the start of this sequence, the city had a large network of strong motion stations (SMSs) already installed, which were able to record a vast database of strong ground motion recordings. Within Christchurch there were seven SMSs as part of the National Strong Motion Network and nine as part of Canterbury regional strong motion network (Avery et al. 2004). Additionally, there were SMSs located in both Lyttelton (LPCC) and Kaiapoi (KPOC), all combined as part of the GeoNet project (GNS Science 2013).

This paper uses this database of strong ground motion records, the observations of liquefaction manifestation at the ground surface, and data from a recently completed extensive geotechnical site investigation program at each SMS to assess a range of liquefaction evaluation procedures for multiple site investigation techniques. The focus of this paper is the SMSs located in the Christchurch CBD, namely Christchurch Botanical Gardens (CBGS), Christchurch Cathedral College (CCCC), Christchurch Hospital (CHHC), and Christchurch Resthaven (REHS). These sites are all within $2.5 \mathrm{~km}$ of each other, and have very diverse soil profile characteristics. Results of the evaluation procedures were compared against the observed liquefaction surface manifestations and the characteristics of the accelerograms recorded at each SMS during the Darfield and Christchurch earthquakes.

\section{GEOTECHNICAL DATA}

Prior to 2011, little information regarding the subsurface geotechnical characteristics of the strong motion station locations in and around Christchurch was available. As noted by Cousins \& McVerry (2010), the soil profiles and site classes at each SMS were assumed from well logs and regional geological knowledge. Therefore, CPT, SPT and borehole data, shear wave velocity $\left(V_{s}\right)$ profiles, and horizontal to vertical spectral ratio measurements $(\mathrm{H} / \mathrm{V})$ in close vicinity to the SMS were used to develop detailed soil profiles at each site.

Initially, existing CPT, borehole and SPT data in the vicinity of each SMS were collected from available sources (CERA 2012). At locations with a paucity of data, an additional program of subsurface site investigations was carried out using CPT and borehole methods where appropriate. At each site, CPT data was used to calculate the soil behaviour type index $\left(I_{c}\right)$ as a function of depth, to enable qualitative comparisons with the borehole log data where available (Robertson \& Wride 1998). Shear wave profiles were developed using dispersion data from the study summarised by Wood et al. (2011) and additional surface wave testing. A combination of active-source and passive-source surface wave techniques were used to resolve the shear stiffness and layering beneath each SMS. Layering characteristics at each site from the subsurface investigations were used to help constrain the layering of the shear wave velocity profile. A summary of the data collated at the CBGS SMS is outlined in Figure 1. Regional geotechnical investigations have shown little change in CPT sounding characteristics before and after major events in the earthquake sequence (Orense et al. 2011). Therefore, although site investigations were carried out following these earthquakes, it can be reasonably assumed that they provide a good representation of the pre-sequence soil profile characteristics.

At each location where borehole cores were available, samples were taken from each of the soil layers to define their grain size distribution and fines content (FC). At the time of writing, the grain size distribution testing of all sand and silty sand layers were completed. At sites where no borehole data was available, the fines content was estimated using the generic correlation between FC and $I_{c}$ proposed by Robertson and Wride (1998). 

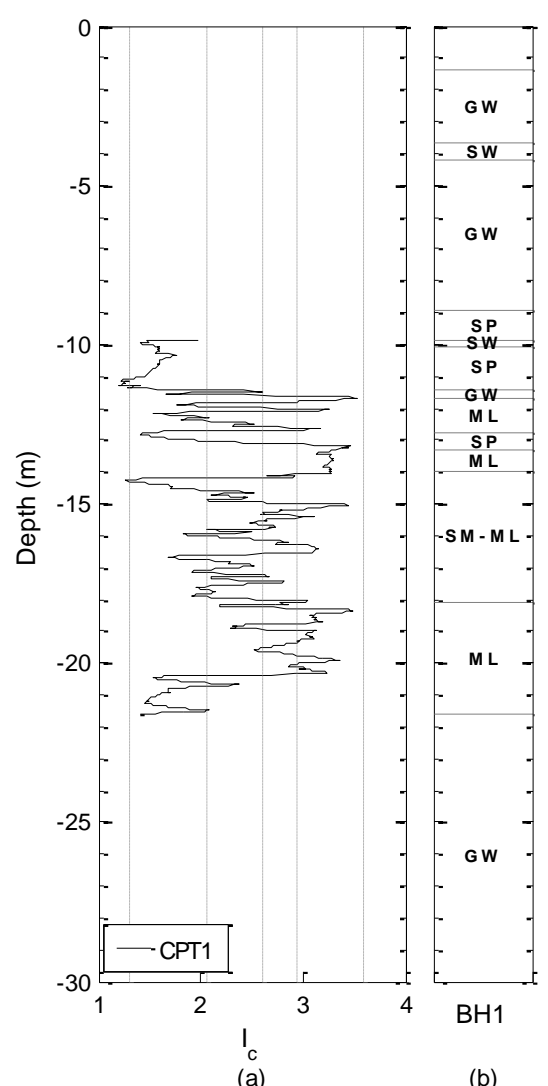

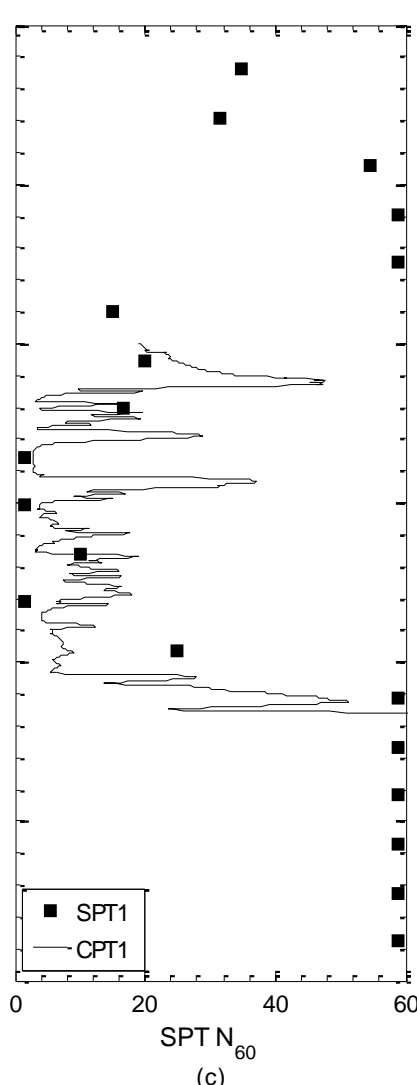

(c)

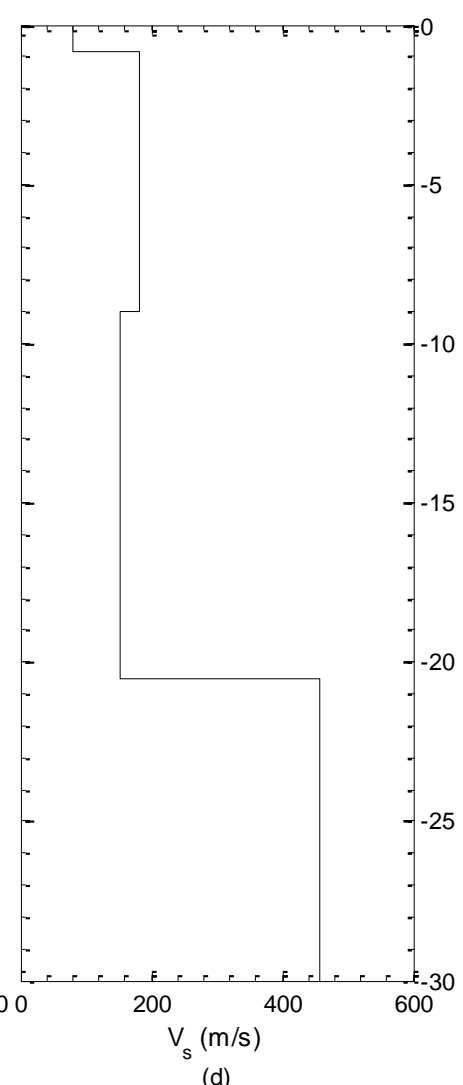

(d)

Figure 1. CBGS geotechnical site investigation summary. (a) soil behaviour type index, (b) borehole BH1 log, (c) SPT and CPT equivalent blow counts, (d) shear wave velocity

\section{LIQUEFACTION EVALUATION PROCEDURES}

Multiple deterministic liquefaction evaluation procedures were applied to each of the site investigation methods available at each SMS location. Calculations were performed using the geometric mean of the horizontal PGA recorded at each SMS for the $M_{w} 7.12010$ Darfield earthquake and the $M_{w} 6.2$ 2011 Christchurch earthquake. The PGA values prior to any manifestation of liquefaction in the accelerograms were used in these calculations. The following procedures were investigated:

- $\quad$ CPT based methods - Youd et al. (2001), Moss et al. (2006), Idriss \& Boulanger (2008)

- $\quad$ SPT based methods - Youd et al. (2001), Cetin et al. (2004), Idriss \& Boulanger (2008)

- $\quad V_{s}$ based methods - Andrus \& Stokoe (2000), Kayen et al. (2013)

A probability of liquefaction $\left(\mathrm{P}_{\mathrm{L}}\right)$ of $15 \%$ was used to represent a deterministic liquefaction evaluation for the procedures of Moss et al, Cetin et al. and Kayen et al. The middle of the range of magnitude scaling factors (MSFs) recommended for the Youd et al. methods were used in this study. The rest of the procedures used the appropriate MSF or DWF (Duration Weighting Factor) detailed in each reference. The relative densities $\left(D_{r}\right)$ were estimated using the relationship given in Robertson and Cabal (2012) for use in the Youd et al. and Cetin et al. procedures. Ground water levels for each event were defined using the guidelines from the Canterbury Geotechnical Database (CERA 2012). At these locations, no potentially liquefiable layers were present above these water table levels. Soil unit weight was assumed to be $17 \mathrm{kN} / \mathrm{m}^{3}$ above the water table, and $19.5 \mathrm{kN} / \mathrm{m}^{3}$ below the water table.

In this paper we focus on the results from the CPT based methodologies. Layers were assumed to be potentially liquefiable in the CPT analyses if $I_{c}<2.6$. The potentially liquefiable layers for the SPT analyses were defined based on the soil type encountered in the borehole and the FC data from laboratory analysis, with only sand and silty sand layers considered in the analyses. At SMS locations 
with borehole and SPT data, the potentially liquefiable layers for the $V_{s}$ based methods were the same as those assumed liquefiable for the SPT based methods. At SMS locations with CPT data only, the potentially liquefiable layers for the $V_{s}$ based methods were the same as those assumed for the CPT based methods.

Data from the liquefaction evaluation procedures were used to define two indicators of the severity of liquefaction, the Liquefaction Potential Index (LPI) (Iwasaki 1984), and the Liquefaction Severity Number (LSN), (van Ballegooy et al. 2012). An approximate relationship between surface manifestation severity and the LPI and LSN values is summarized in Table 1 . Work by Toprak \& Holtzer (2003) suggested that there is unlikely to be any surface manifestations for an LPI less than 5.

These evaluation procedures were compared against two physical indicators of liquefaction: 1) the observed severity of liquefaction surface manifestations following the Darfield and Christchurch earthquakes, defined using both post-event site visits by the authors and high aerial and satellite imagery taken soon after each earthquake; 2) the characteristics of the accelerograms recorded at the SMSs, with liquefaction indicated by acceleration spikes characteristic of cyclic mobility, and reduced high frequency content in the latter part of the record. A summary of the observed liquefaction surface manifestations and the surface ground motion characteristics at each SMS is provided in Table 2.

Table 1. Liquefaction surface manifestation severity as a function of LPI and LSN

\begin{tabular}{|c|c|c|c|c|}
\hline Severity & None & Minor & Moderate & Major \\
\hline LPI & 0 & $0-5$ & $5-15$ & $15+$ \\
\hline LSN & 0 & $0-20$ & $20-50$ & $50+$ \\
\hline
\end{tabular}

\section{CASE STUDIES}

Two case studies of the liquefaction characteristics and evaluations at two SMS locations are described in detail in this section.

\section{Christchurch Botanical Gardens (CBGS)}

The CBGS SMS is located on the western edge of the Christchurch CBD. The soil profile characteristics at the CBGS SMS are summarized in Figure 1. Borehole logs indicate approximately $9 \mathrm{~m}$ of gravels at the surface with SPT $N_{60}$ values of 30 and above. Beneath these surface gravels are interbedded layers of sands, sandy silts and silts down to $21 \mathrm{~m}$. $I_{c}$ values from CPT data also indicate the variability of deposits within the 9-21 m depth range. The fines content for the sand and silty sand layers ranged from 1.1 to $15.3 \%$. Below this the dense Riccarton Gravel deposits were encountered.

There was no clear manifestation of liquefaction effects at the ground surface in the immediate vicinity of the SMS or evidence of liquefaction in the accelerogram from the Darfield earthquake (Figure 3a). Again there was no clear manifestation of liquefaction effects near the SMS following the Christchurch earthquake. An aerial view of the CBGS location is shown in Figure 2 for both these events. The lighter spots in the grass surrounding the SMS in Figure $2 \mathrm{~b}$ were confirmed as dry grass areas and not surface ejecta by ground reconnaissance following the Christchurch earthquake. A few hundred metres to the north of the SMS, significant volumes of ejecta were evident at the ground surface in North Hagley Park following the Christchurch earthquake. However, the accelerogram from the Christchurch earthquake in Figure $3 \mathrm{~b}$ showed a clear indication of liquefaction of the underlying soils, with characteristic acceleration spikes and reduced high frequency content in the latter part of the record (Bradley \& Cubrinovski 2011). This indicates that liquefaction likely occurred during the Christchurch earthquake. However, the thick gravel layer near the surface simply prevented surface manifestation of liquefaction near the SMS.

Using the CPT, SPT and $V_{s}$ data summarized in Figure 1, all the liquefaction evaluation procedures outlined in the previous section were applied. The geometric mean PGA was equal to $0.16 \mathrm{~g}$ and $0.33 \mathrm{~g}$ for the Darfield and Christchurch earthquakes, respectively. For the Darfield earthquake only a small 
number of very thin layers were shown to have a factor of safety slightly less than one throughout the soil profile. For the Christchurch earthquake multiple layers up to $40 \mathrm{~cm}$ in thickness were shown to liquefy throughout the soil profile, with the factors of safety of these layers as low as 0.5 for some of the methodologies. These potentially liquefiable layers sit below the approximately $9 \mathrm{~m}$ of surface gravels. These calculations correlate well with the accelerogram characteristics for each event.

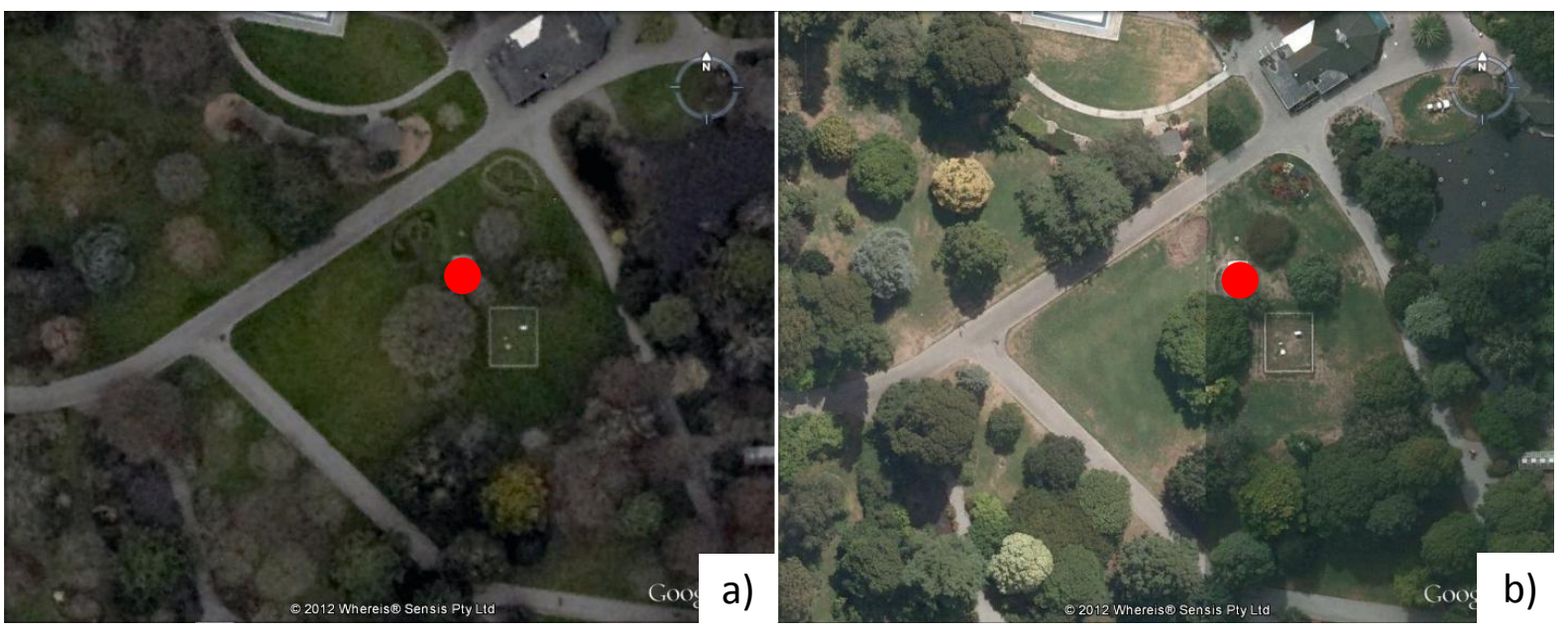

Figure 2. CBGS liquefaction surface manifestation a) Darfield earthquake; b) Christchurch earthquake

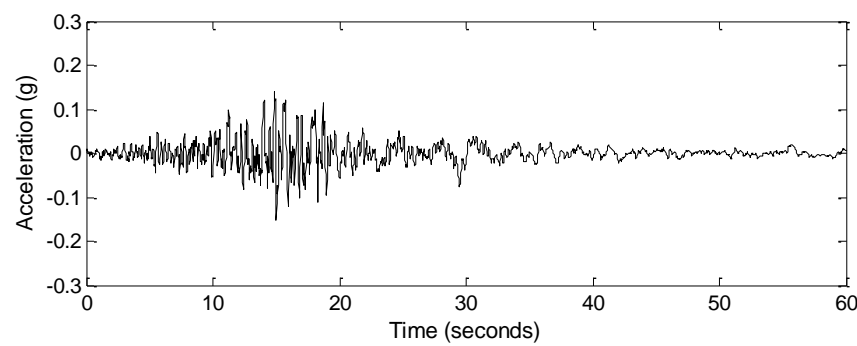

a)

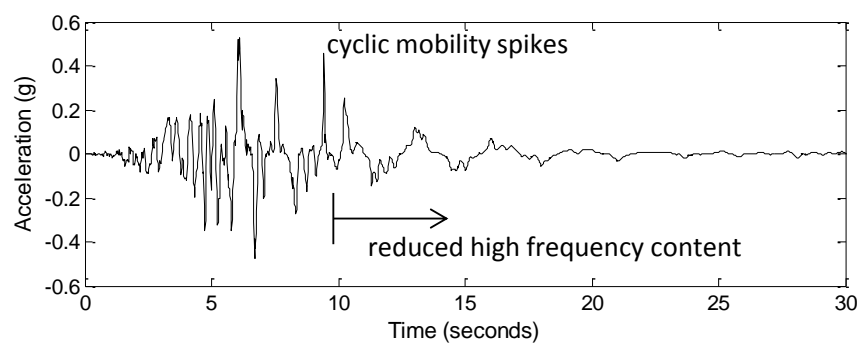

b)

Figure 3. CBGS accelerogram for the a) Darfield earthquake; b) Christchurch earthquake

Using the CPT evaluation procedures, the LSN was equal to 0.2-0.3, a range that correlates to no surface effects. This compares well with the lack of surface manifestations, as only the top $10 \mathrm{~m}$ of the soil profile included in the calculation of LSN. Clearly the crust thickness is important as it has an influence on the presence of any surface manifestations. The LPI values for each site investigation method and liquefaction evaluation procedure for the Christchurch earthquake are summarized in Figure 4. There is range in the LPI values for each site investigation method and across each of the methods. Similar layers were shown to liquefy using all of the CPT and SPT based methods, with LPI values suggesting minor surface liquefaction manifestations. This has a reasonable correlation with the observed surface manifestations, and if only the top $10 \mathrm{~m}$ of the soil profile was taken into account the calculated surface manifestation severities would be similar to that suggested by the LSN calculations. 
The $V_{s}$ based methods showed the most significant variation in LPI values. The Andrus and Stokoe method suggesting liquefaction would have taken place in most of the sand and silty sand layers, with the final LPI value indicating moderate liquefaction surface effects, clearly not correlating well with what was observed. This method resulted in very low factors of safety in the liquefiable layers, which correlates well with the observed ground motions. At the other end of the range, the Kayen et al. approach suggested that none of the soil profile was expected to liquefy. Although the LPI value relates well with the observed surface effects, this method seems to over predict the factor of safety against liquefaction, as the ground motion characteristics suggest significant liquefaction of the underlying layers.
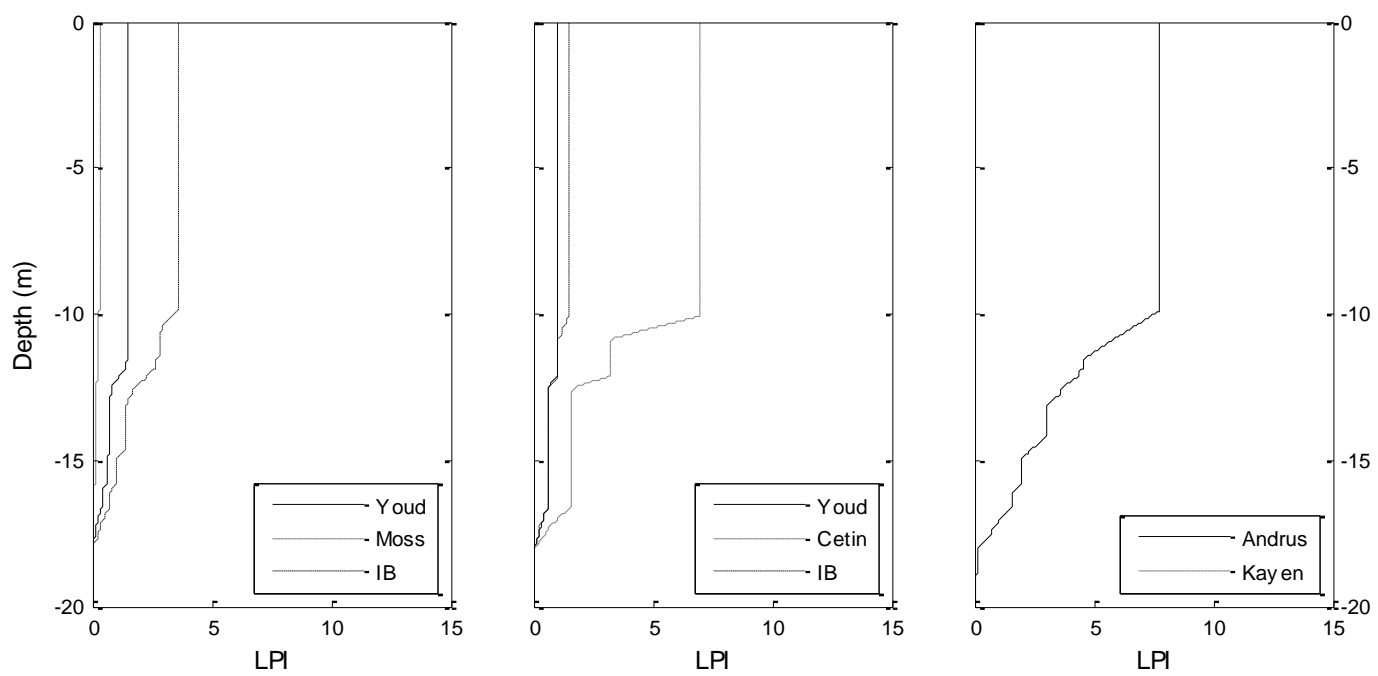

Figure 4. CBGS LPI calculations for the Christchurch earthquake a) CPT based methods; b) SPT based methods; c) $V_{s}$ based methods
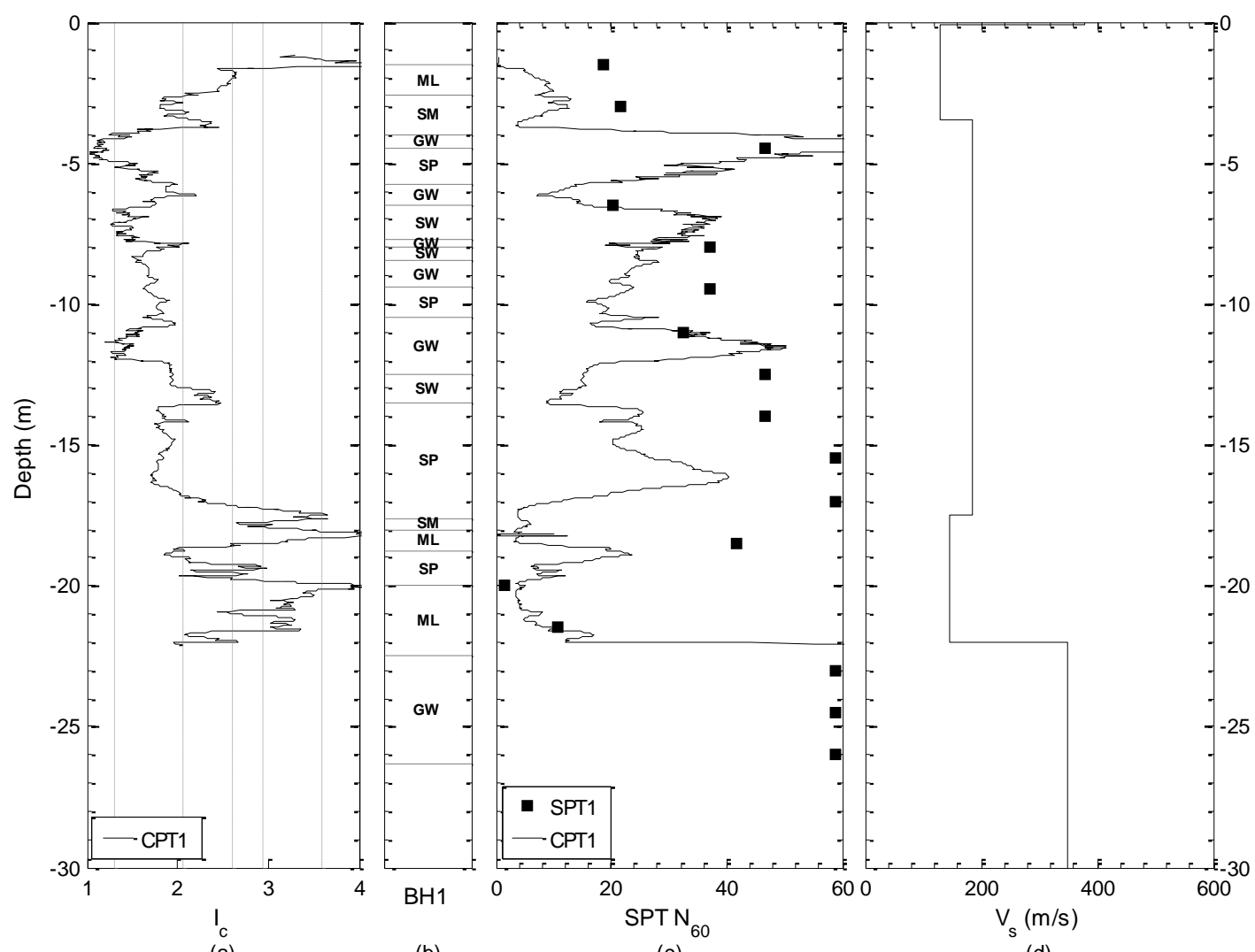

Figure 5. CHHC geotechnical site investigation summary (a) soil behaviour type index, (b) borehole BH1 log, (c) SPT and equivalent CPT blow counts, (d) shear wave velocity 


\section{Christchurch Hospital (CHHC)}

The CHHC SMS is located at the south western corner of the Christchurch CBD. Borehole logs indicate layered deposits of sands and gravels to a depth of between 10 and $15 \mathrm{~m}$. A stiff sand layer is located beneath these interbedded layers, varying in thickness by between 4 and $8 \mathrm{~m}$. A soft, $4 \mathrm{~m}$ thick layer of silts and organics sits between the sand layer and the stiff Riccarton Gravels below. The Riccarton Gravels are located at a depth of approximately $22 \mathrm{~m}$.

There was no clear manifestation of liquefaction effects at the ground surface in the immediate area surrounding the SMS following the Darfield earthquake (Figure 6a), and moderate volumes of ejecta in the area immediately adjacent and surrounding the SMS following the Christchurch earthquake (Figure 6b). The acceleration record from the Christchurch earthquake in Figure 7 clearly indicated liquefaction of the underlying soils, with characteristic acceleration spikes and reduced high frequency content in the latter part of the record (Bradley \& Cubrinovski 2011). The acceleration record from the Darfield earthquake showed no indication of the occurrence of liquefaction in the underlying soils.

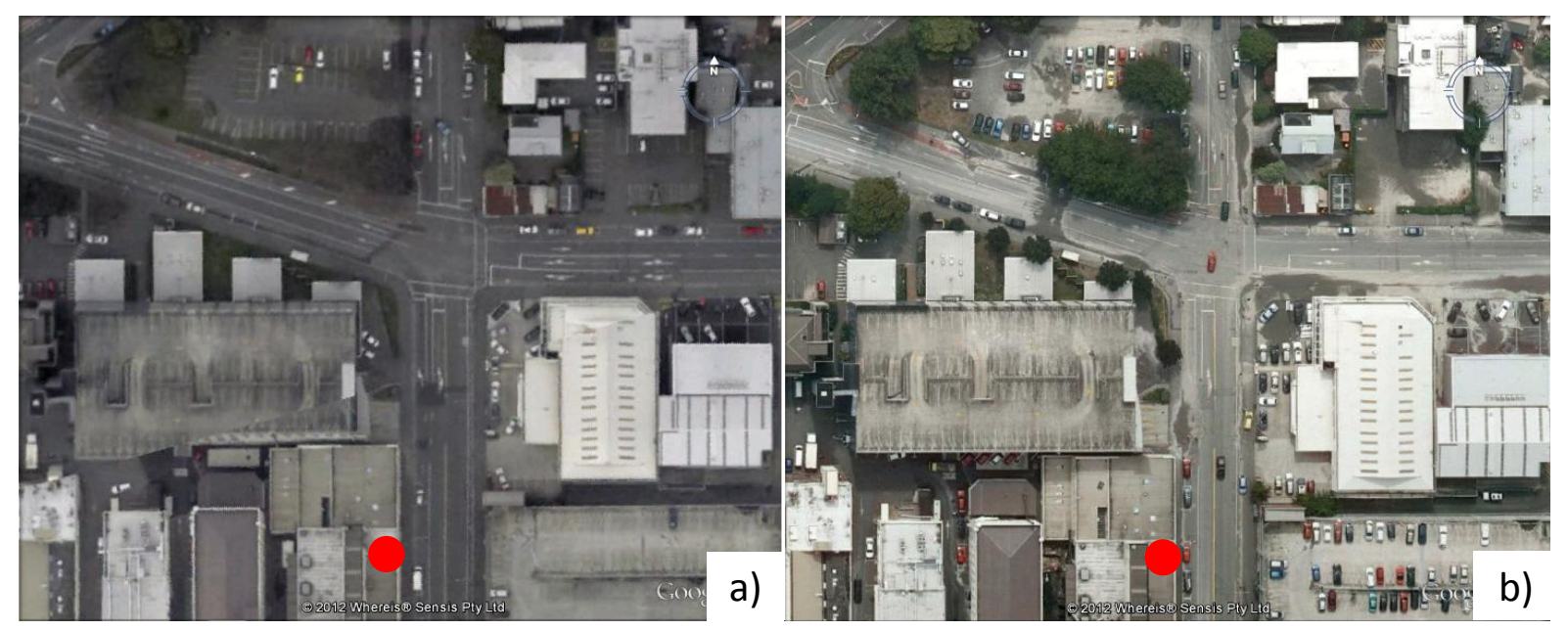

Figure 6. CHHC liquefaction surface manifestation a) Darfield earthquake; b) Christchurch earthquake

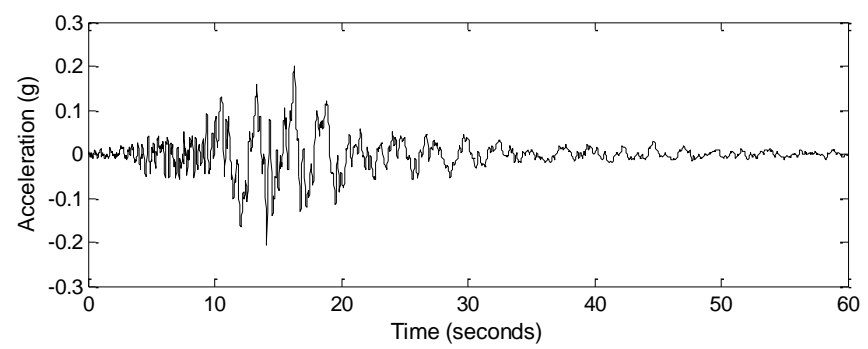

a)

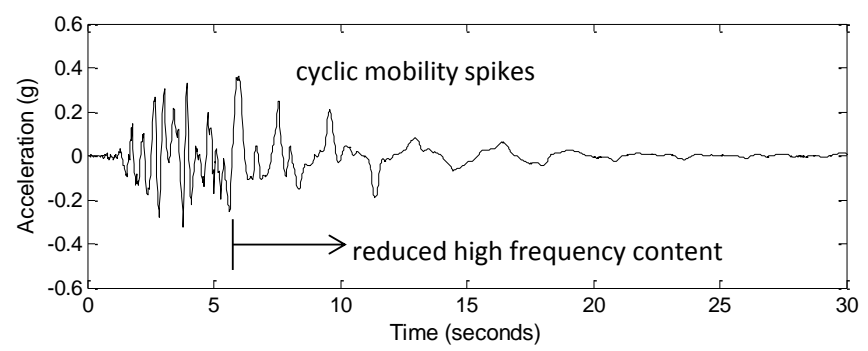

b)

Figure 7. CHHC accelerogram for the 2011 Christchurch earthquake

The liquefaction evaluation procedures for CPT and $V_{s}$ outlined in the previous section were applied. The geometric mean PGA was equal to $0.17 \mathrm{~g}$ and $0.37 \mathrm{~g}$ for the Darfield and Christchurch earthquakes, respectively. For the Darfield earthquake only a small number of thin layers were shown to have a factor of safety less than one throughout the soil profile for the majority of the evaluation 
procedures. For the Christchurch earthquake much thicker layers were predicted to liquefy throughout the soil profile, with much lower factors of safety. The CPT calculations generally correlate well with the accelerogram characteristics recorded during each event. The Kayen et al. $V_{s}$ procedure resulted in factors of safety very close to one in the liquefiable layers, suggesting a liquefaction severity less that that observed in the ground motion records.

A summary of the LPI and LSN calculations are presented in Figure 8. The CPT based LPI for the Darfield earthquake was 0.4-2.8, and the LSN was equal to 4.4-7.4, both suggesting that there would be minimal surface manifestation effects, correlating well with what was observed. For the Christchurch earthquake there was a significant increase in these values, with the LPI equal to 2.7-14.1 and LSN equal to 10.1-16.9. There is a large range in the LPI values, with the lower end of the scale suggesting surface manifestation effects less severe than what was observed. The LSN values have a smaller range and also suggest surface manifestations less severe than what was observed. The LPI calculated using the $V_{s}$ data again had a large range, with the Kayen et al. procedure resulting in a value of almost zero, compared to 5.3 for the Andrus \& Stokoe procedure. Again these both suggest surface manifestation effects that were less severe that that observed. The $V_{s}$ based approaches had liquefiable layers defined using the CPT $I_{c}$ values. The LPI value for Andrus \& Stokoe procedure is developed in two main layers, while the CPT based methods show a gradual increase through multiple layers.
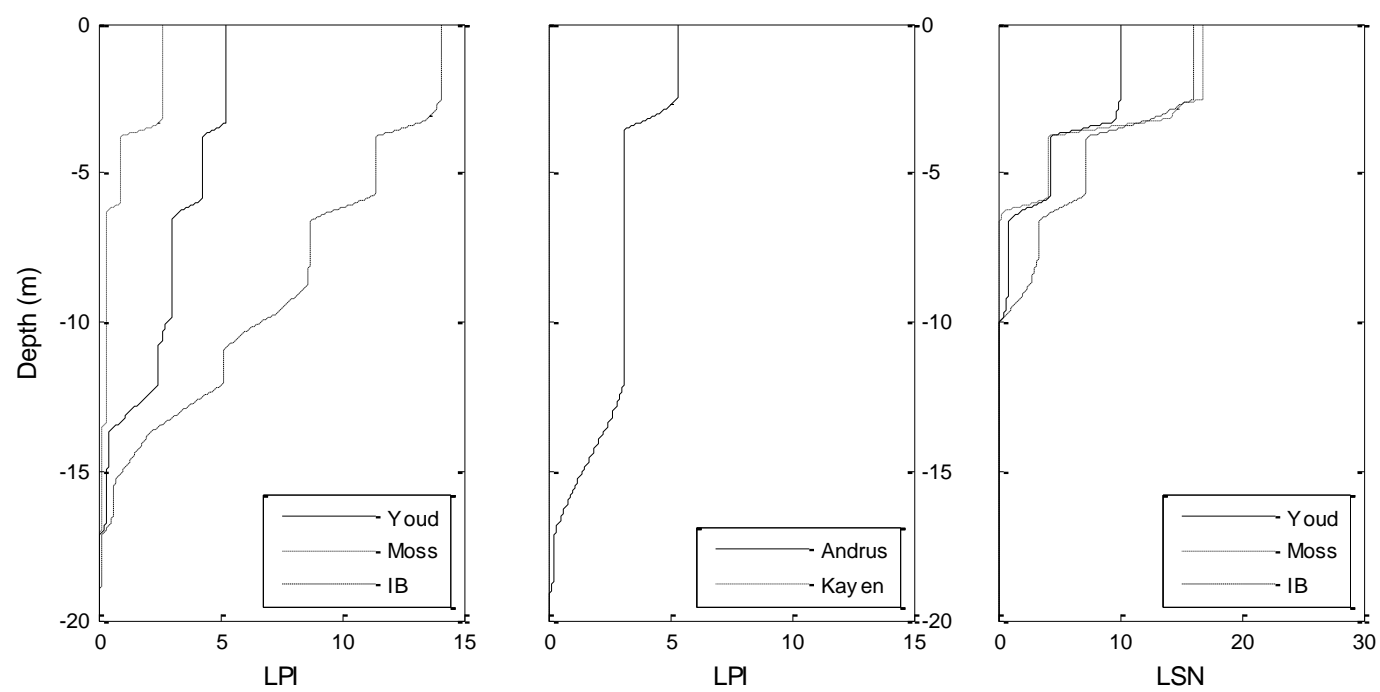

Figure 8. CHHC calculations for the Christchurch earthquake a) CPT based LPI; b) $V_{s}$ based LPI; c) CPT based LSN

\section{SUMMARY}

A summary of the CPT based LPI and LSN outlined in the previous section and those at the two remaining Christchurch SMSs is provided in Table 2. These are compared against any evidence of liquefaction in the ground motion records and at the ground surface for the Darfield and Christchurch earthquakes. In general the initial factor of safety portion of these calculations showed a good correlation to the sites where the recorded ground motions showed evidence of liquefaction, with factors of safety less than one.

At REHS there was no manifestation of liquefaction effects at the ground surface in the immediate area surrounding the SMS following any of the major earthquakes in the Canterbury earthquake sequence. The indicator values calculated for both the Darfield and Christchurch earthquakes did not correlate well with these observations, with both the LPI and LSN values suggesting minor severity during the Darfield earthquake, and moderate severity during the Christchurch earthquake. However, this may be due to the presence of a thin gravel layer at the ground surface at this location. 
Minor volumes of ejecta were evident in the area surrounding the CCCC SMS following the Christchurch earthquake, with a few isolated sand boils approximately $50 \mathrm{~m}$ from the SMS location. The severity of the surface manifestation at CCCC was much less that that at CHHC for this event, however the LSN values for both sites were very similar. For the Darfield earthquake the LPI and LSN values suggesting minor-moderate surface manifestations, while in reality there was no manifestation and no evidence of liquefaction in the ground motion records.

For sites that had no evidence of liquefaction manifestation at the ground surface, and no evidence of liquefaction in the ground motion records, the LPI values ranged from 0 to 7.7, and the LSN values ranged from 0.1 to 28 . This is a large range of values for these sites with no surface manifestation, with the lack of evidence from surface acceleration records also suggesting that the triggering of liquefaction would only be marginal.

For multiple sites there may have been severe liquefaction of a layer at depth, as indicated by liquefaction evaluation analyses and/or inferred from the characteristics of the recorded surface acceleration time series, however due to a non-liquefiable crust layer this was unable to manifest itself at the ground surface. This lack of surface manifestation was not able to be captured in either the LPI and LSN methodologies across all the SMS locations, and for both earthquakes.

Table 2. Summary of the evidence of liquefaction from observed ground motions, surface manifestations and CPT based liquefaction indicators

\begin{tabular}{|c|c|c|c|c|c|c|c|c|}
\hline SMS & \multicolumn{4}{|c|}{ Darfield earthquake } & \multicolumn{4}{c|}{ Christchurch earthquake } \\
\hline & Ground & Surface & LPI & LSN & Ground & Surface & LPI & LSN \\
\hline & motions & evidence & & & motions & evidence & & \\
\hline CBGS & $\mathrm{N}$ & $\mathrm{N}$ & $0-1.1$ & $0.1-0.2$ & $\mathrm{Y}$ & $\mathrm{N}$ & $0.3-3.6$ & $0.2-0.3$ \\
\hline CCCC & $\mathrm{N}$ & $\mathrm{N}$ & $1.7-7.7$ & $10.8-16.1$ & $\mathrm{Y}$ & $\mathrm{Y}$ & $1.8-7.5$ & $7.1-16.4$ \\
\hline CHHC & $\mathrm{N}$ & $\mathrm{N}$ & $0.4-2.8$ & $4.4-7.4$ & $\mathrm{Y}$ & $\mathrm{Y}$ & $2.7-14.1$ & $10.1-16.9$ \\
\hline REHS & $\mathrm{N}$ & $\mathrm{N}$ & $3.4-6.6$ & $15.2-28.0$ & $\mathrm{Y}$ & $\mathrm{N}$ & $7.0-11.1$ & $17.3-32.3$ \\
\hline
\end{tabular}

\section{CONCLUSIONS}

Using the database of strong ground motion recordings from the Canterbury earthquake sequence, the observations of liquefaction manifestation at the ground surface, and data from a recently completed extensive geotechnical site investigation program at each SMS, a range of liquefaction evaluation procedures for multiple site investigation techniques were assessed.

In general, the characteristics of the recorded accelerograms at each SMS correlated well with the liquefaction evaluation procedures, with lower liquefaction factors of safety predicted at sites with clear liquefaction identifiers in the ground motions. However, at sites that likely liquefied at depth (as indicated by evaluation procedures and/or inferred from the characteristics of the recorded surface acceleration time series), the presence of a non-liquefiable crust layer at many of the SMS locations prevented the manifestation of any surface effects. This meant that there was not a good correlation between surface manifestation and two surface manifestation indices, the Liquefaction Potential Index (LPI) and the Liquefaction Severity Number (LSN).

\section{AKNOWLEDGEMENTS}

This primary support for this research project was provided by Earthquake Commission (EQC) Biennial Grant 12/629. L. Wotherspoon's position at the University of Auckland is funded by the EQC. The primary support for the US authors was provided by the U.S. National Science Foundation (NSF) grant CMMI-1306261. However, any opinions, findings, and conclusions or recommendations 
expressed in this material are those of the authors and do not necessarily reflect the views of the National Science Foundation.

We acknowledge the Canterbury Geotechnical Database for some of the site investigation data used in this study. EQC, CERA, their data suppliers and their engineers, Tonkin \& Taylor, have no liability to any user of this data or for the consequences of any person relying on them in any way. We acknowledge the New Zealand GeoNet project and its sponsors EQC, GNS Science and LINZ, for providing some of the data used in this study. We also thank the land owners at all strong motion stations for their cooperation during this study, and the support of McMillans Drilling.

\section{REFERENCES}

Andrus RD and Stokoe II KH. (2000). "Liquefaction resistance of soils from shear wave velocity," Journal of Geotechnical and Geoenvironmental Engineering, ASCE, 126(11), 1015-1025.

Avery HR, Berrill JB, Coursey PF, Deam BL, Dewe MB, Francois CC, Pettinga JR, and Yetton MD. (2004). "The Canterbury University strong-motion recording project," Proc. 13th WCEE, Vancouver, August 1- 6, 2004.

Bradley BA and Cubrinovski, M. (2011). "Near-source strong ground motions observed in the 22 February 2011 Christchurch earthquake," Seismological Research Letters, 82, 853-865.

Brown LJ and Weeber JH. (1992). Geology of the Christchurch urban area. Institute of Geological and Nuclear Sciences, Lower Hutt.

Canterbury Earthquake Recovery Authority (CERA) (2012). Geotechnical database for Canterbury earthquake sequence. https://canterburygeotechincaldatabase.projectorbit.com.

Cetin KO, Seed RB, Der Kiureghian A, Tokimatsu K, Harder LF, Kayen RE and Moss RES. (2004). "Standard penetration test-based probabilistic and deterministic assessment of seismic soil liquefaction potential," Journal of Geotechnical and Geoenvironmental Engineering, ASCE, 130(12), 1314-1340.

Cousins J and McVerry G. (2010). "Overview of strong motion data from the Darfield earthquake," Bulletin of the NZSEE, 43(4), 222-227.

GNS Science. (2013). GeoNet http://www.geonet.org.nz (accessed June 15, 2013)

Idriss IM and Boulanger RW. (2008). Soil liquefaction during earthquakes. Monograph MNO-12, Earthquake Engineering Research Institute, Oakland, CA, $261 \mathrm{pp}$.

Iwasaki T, Arakawa T and Tokida KI. (1984). "Simplified procedures for assessing soil liquefaction during earthquakes," International Journal of Soil Dynamics and Earthquake Engineering, 3, 49-58.

Kayen RE, Moss RES, Thompson EM, Seed RB, Cetin KO, Der Kiureghian A, Tanaka Y and Tokimatsu K. (2013). "Shear-wave velocity-based probabilistic and deterministic assessment of seismic soil liquefaction potential," Journal of Geotechnical and Geoenvironmental Engineering, ASCE, 139(3), 407-419.

Moss RES, Seed RB, Kayen RE, Stewart JP, Der Kiureghian A, and Cetin, KO. (2006). "CPT-based probabilistic and deterministic assessment of in situ seismic soil liquefaction potential," Journal of Geotechnical and Geoenvironmental Engineering, ASCE, 132(8), 1032-1051.

Orense RP, Pender MJ and Wotherspoon LM. (2011). "Analysis of soil liquefaction during recent Canterbury (New Zealand) earthquakes,' Geotechnical Engineering Journal SEAGS \& AGSSEA, 42(3), 8-17.

Robertson PK and Cabal KL. (2012). Guide to Cone Penetration Testing for Geotechnical Engineering, $5^{\text {th }}$ edition, Gregg Drilling \& Testing, 131pp.

Robertson PK and Wride CE. (1998). "Evaluating cyclic liquefaction potential using the cone penetration test," Canadian Geotechnical Jnl., 35, 442-459.

Toprak S and Holtzer TL. (2003). "Liquefaction potential index: field assessment," Journal of Geotechnical and Geoenvironmental Engineering, ASCE, 129(4), 315-322.

Van Ballegooy S, Malan PJ, Jacka ME, Lacrosse VIMF, Leeves JR and Lyth JE. (2012). "Methods for characterising effects of liquefaction in terms of damage severity," Proc. 15 $5^{\text {th }}$ World Conference of Earthquake Engineering, Lisbon, Portugal.

Wood CM, Cox BR, Wotherspoon LM and Green RA. (2011). "Dynamic site characterization of Christchurch strong motion stations," Bulletin of the NZSEE, 44(4), 195-204.

Youd TL, Idriss IM, Andrus RD, Arango I, Castro G, Christian JT, Dobry R, Finn WDL, Harder LF, Hynes ME, Ishihara K, Koester JP, Liao SSC, Marcuson III WF, Martin GR, Mitchell JK, Moriwaki Y., Power MS, Robertson P.K, Seed RB, and Stokoe II KH. (2001). "Liquefaction Resistance of soils: Summary report from the 1996 NCEER and 1998 NCEER/NSF workshops on evaluation of liquefaction resistance of soils," Journal of Geotechnical and Geoenvironmental Engineering, 127(4), 297-313. 